\title{
BMJ Open Equity and determinants of routine child immunisation programme among tribal and non-tribal populations in rural Tangail subdistrict, Bangladesh: a cohort study
}

Aminur Rahman, ${ }^{1}$ Ashek Ahmed Shahid Reza, ${ }^{2}$ Badrul Alam Bhuiyan, ${ }^{3}$ Nurul Alam, Shushil K Dasgupta, ${ }^{1}$ Shabnam Mostari, ${ }^{4}$ Iqbal Anwar ${ }^{1}$

To cite: Rahman A, Reza AAS, Bhuiyan BA, et al. Equity and determinants of routine child immunisation programme among tribal and non-tribal populations in rural Tangail subdistrict, Bangladesh: a cohort study. BMJ Open 2018;8:e022634. doi:10.1136/ bmjopen-2018-022634

\section{- Prepublication history for} this paper is available online. To view these files, please visit the journal online (http://dx.doi org/10.1136/bmjopen-2018022634).

Received 7 March 2018

Revised 12 June 2018

Accepted 14 September 2018

Check for updates

(C) Author(s) (or their employer(s)) 2018. Re-use permitted under CC BY-NC. No commercial re-use. See rights and permissions. Published by BMJ.

For numbered affiliations see end of article.

Correspondence to Dr Aminur Rahman; draminur@icddrb.org

\section{ABSTRACT}

Objectives The study estimated valid vaccination coverage of under 5 children in a rural area under Tangail subdistrict and examined their sociodemographic correlates including ethnicity.

Setting The study sites are three primary areas where tribal and non-tribal population resides together in a rural subdistrict of Bangladesh.

Participants Routine vaccination information of a cohort of 2802 children, born between 1 January 2011 and 31 December 2012, were retrieved from the Expanded Program on Immunization (EPI) registers maintained by the health assistants. Collected data were entered in an Oracle-based computer program. Univariate, bivariate and multivariate analyses were performed in SPSS V.20 to explore coverage and differentials for full valid vaccination coverage in the study area.

Results Valid vaccination coverage was $90.6 \%$ among tribal population and $87.3 \%$ among non-tribal population $(p=0.25)$. Compared with females, males had higher valid vaccination coverage ( $89.2 \%$ vs $85.9 \%$ ) and lower invalid ( $5.4 \%$ vs $6.9 \%)$ and no-coverage $(5.3 \%$ vs $7.3 \%)(p=0.03)$. Households with mobile phones had higher valid coverage ( $90.9 \%$ vs $86.5 \%)$ and lower invalid ( $4.5 \%$ vs $6.7 \%$ ) and no coverage $(4.5 \%$ vs $6.9 \%)$ compared with those without mobile phones $(p=0.01)$. Coverage of valid vaccination was higher among children of Oronkhola union than in children of the other two unions.

Conclusion The study documented that valid vaccination coverage was high in this rural area, and there was no significant ethnic variation which was one of the strengths of the national EPI. However, there is significant variation by gender of the child, household ownership of mobile phones and geographical location of households.

\section{INTRODUCTION}

Over the last few decades, remarkable improvement has been made towards the development of national immunisation programmes throughout the world. ${ }^{1}$ The Expanded Program on Immunization (EPI) has the major contribution to this tremendous achievement. The EPI was launched in 1974 and supported
Strengths and limitations of this study

- This is the first population-based study that provides a comprehensive overview of the Expanded Program on Immunization coverage among tribal and non-tribal children in Bangladesh and examined their sociodemographic correlates.

- There was no disparity on vaccination coverage among tribal and non-tribal populations.

- Accessibility to the mobile phone significantly changes the coverage, and male child is less likely not to be vaccinated than female child.

- This study was conducted in a smaller scale, and the result of this study may not represent the overall picture of Bangladesh.

by the WHO and implemented by Unicef. The aim of this programme is to prevent infant and child deaths from six vaccine-preventable infectious diseases (ie, diphtheria, whooping cough, tetanus, measles, poliomyelitis and tuberculosis). ${ }^{2-4}$ In the past, these diseases were a global public health burden, as they were the major causes of child deaths in the 20th century. ${ }^{5-7}$ Proper immunisation against these infectious diseases is one of the most successful cost-effective public health interventions because this programme not only saves the lives of millions of children but also reduces morbidity, including disability. ${ }^{8-11}$ The goal of the EPI was to provide immunisation for all children by 1990 in order to prevent the above-mentioned six vaccine-preventable diseases and to eradicate polio, as per the lesson learnt from the successful eradication of smallpox. ${ }^{12-14}$

The implementation of the EPI has already been shown to be a great success globally; for instance, polio has almost been eradicated, deaths from global measles have dropped by $78 \%$ and maternal and neonatal tetanus has 


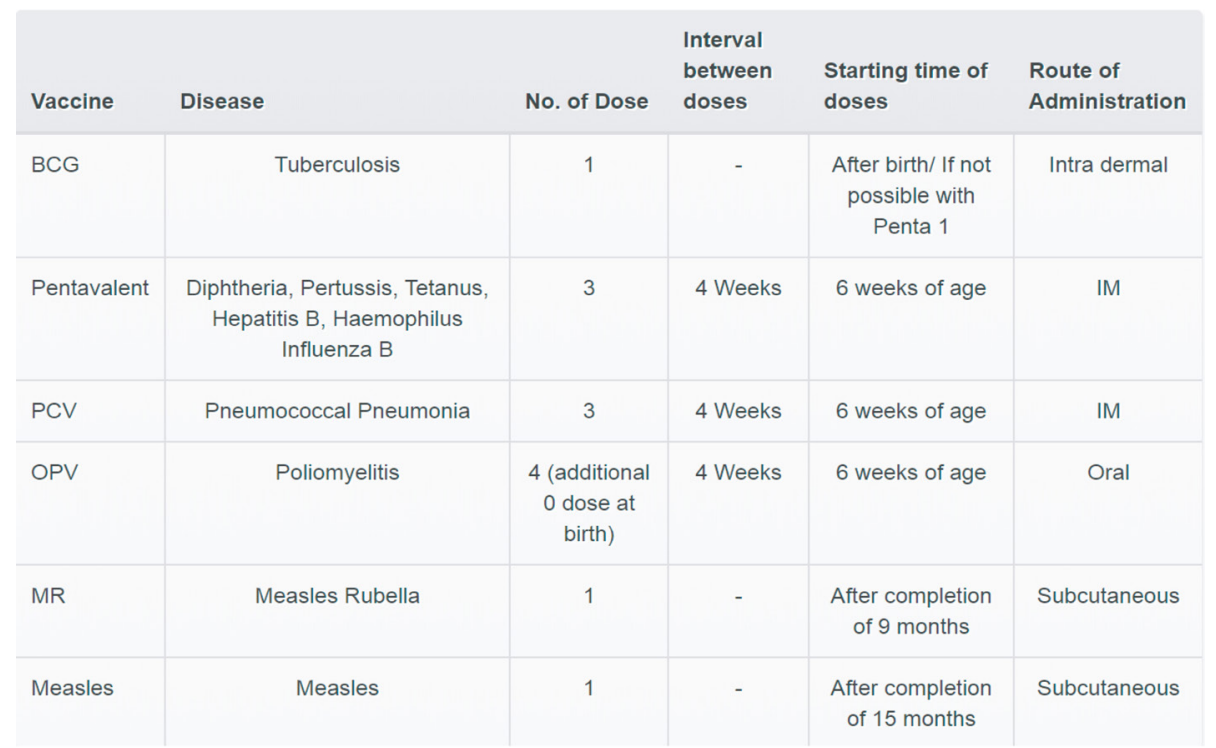

Figure 1 Expanded Program on Immunization schedule. IM, intramuscular; MR, measles-rubella; OPV, oral polio vaccine; PCV, pneumococcal conjugate vaccine.

been successfully eliminated in 58 high-risk countries. ${ }^{15-18}$ A number of research studies have been conducted around the world to evaluate the impact of the EPI. A study conducted in a rural part of India evaluated immunisation coverage and reported that only $60.9 \%$ of children had an immunisation card, and the proportion of immunisation was higher for male children than female children $(87.6 \%$ vs $85.5 \%) .{ }^{19}$ Several studies have reported the occurrence of dropout from EPI, and different reasons for dropout include the unavailability of children and a number of sociodemographic factors. ${ }^{19-21}$ Ethnicity also plays a major role in vaccination coverage which has been demonstrated by several research studies in several countries. In India, tribal people had better immunisation coverage than minor groups, and children were fully vaccinated in Assam, Uttar Pradesh, Aurunachal, Rajasthan and Nagaland. ${ }^{22}$ An extensive literature review revealed that until recently, no such study has ever been conducted in Bangladesh.

EPI was formally launched in Bangladesh in 1979 as a part of initiatives taken by the WHO ${ }^{23} \mathrm{EPI}$ is the most successful programme run by the Government of Bangladesh. From 1987-2000, approximately 1.2 million deaths have been prevented in Bangladesh through EPI. ${ }^{24}$ It was also possible for Bangladesh to eradicate polio through the successful implementation of EPI, and the WHO declared Bangladesh a polio-free region in 2006. ${ }^{25}$ Subsequently, additional vaccines were included with the routine EPI schedule (figure 1), namely, the hepatitis B vaccine was included in 2003, the haemophilus influenza type B (Hib) vaccine was included in 2009 and a second dose of the measles-mumps-rubella vaccine was introduced in 2012. ${ }^{26-28}$

A number of research studies have been conducted to assess the immunisation status in Bangladesh. One study reported that approximately $60 \%$ rural children were fully immunised, whereas other studies have reported that immunisation coverage was 99\% for BCG, 93\% for OPV and $83 \%$ for measles. ${ }^{29} 30$ A number of surveys have also provided the regional distribution of vaccination coverage: crude vaccination coverage was the highest in Rajshahi division (96.8\%) and the lowest in Sylhet division $(88.6 \%)$ in Bangladesh. ${ }^{31}$ Although a few studies have reported findings from vaccination coverage among tribes, they could not reveal data related to equity distribution and sociodemographic variation in terms of vaccination coverage in tribal and non-tribal populations in Bangladesh.

\section{OBJECTIVE}

The aim of the present study is to estimate the valid vaccination coverage of EPI among tribal and non-tribal population in a rural area under Tangail subdistrict and to explore the distribution of vaccination coverage on the basis of sociodemographic factors (eg, ethnicity, gender, geographical location and mobile phone ownership). This study considers EPI a successful health programme in Bangladesh, and this success can be showcased for other low-income and middle-income countries for their learning and development. However, there are still some pockets (hard-to-reach areas and tribal population) where coverage is far behind that presented in national reports. ${ }^{32}$

\section{METHODS}

\section{Study design and data collection procedure}

We conducted a cohort study based on the analysis of routine EPI data, and a few variables such as mobile phone information, tribal and non-tribal population were extracted from the health assistant (HA) registers 
from the years 2011 and 2012. A cohort of 2802 children (registered by the HA) was included in the study, and the data were entered through an Oracle-based computer program which was used for analysis. A data entry software was developed for capturing the data with required validity and ranges, and valid value checks were incorporated into this software. For any inconsistencies, validation checks were done in consultation with the HA registrar books and the field site visits.

In this data analysis, we have examined the cohort born between 1 January 2011 and 31 December 2012, and we followed up with these individuals until the completion of their immunisations. Missing data were addressed by frequent field visit of researchers. In addition to this, researchers sat with respective health workers and asked them to collect if the data were missing.

\section{Study area}

This study was conducted in three unions, namely Aushnara, Solakuri and Aronkhola under the Madhupur upazila/subdistrict (six unions and one municipal area) of the Tangail district in Bangladesh. These three unions were selected purposively that fulfilled the following inclusion criteria: both tribal and non-tribal populations lived together in these unions, and they were not located far from Dhaka. These locations were helpful in enabling EPI and Directorate General of Health Service (DGHS) managers to visit the sites to validate information when required. Muslims comprise the predominant population within these three unions, and the proportion of tribal people was nearly double in one of the unions (Solakuri) compared with the other two unions (table 1). The literacy rate was similar across the three unions, ranging from $34 \%$ to $40 \%$.

\section{Existing procedure of data collection by EPI}

In rural Bangladesh, the lowest administrative unit is a ward which has an average population of approximately 8000 to 10000 . Based on the population, each rural (old) ward was divided into eight imaginary sub-blocks. Each sub-block has an outreach centre (ORC) for vaccination and operates once a month. In Bangladesh, the total number of rural wards is 13494 , and based on the above operational strategy, the number of outreach sites in rural areas are $13494 \times 8=107952$. In addition to the outreach sessions, fixed sessions are also held in all the

\begin{tabular}{|c|c|c|c|}
\hline $\begin{array}{l}\text { Population } \\
\text { characteristics }\end{array}$ & $\begin{array}{l}\text { Aushnara } \\
(n=52431) \%\end{array}$ & $\begin{array}{l}\text { Solakuri } \\
(n=34499) \%\end{array}$ & $\begin{array}{l}\text { Aronkhola } \\
(n=58784) \%\end{array}$ \\
\hline Tribal & 7.1 & 13.6 & 8.9 \\
\hline Muslim & 74.2 & 46.2 & 59.1 \\
\hline Other religion & 25.8 & 53.8 & 40.9 \\
\hline Literacy rate & 37.7 & 33.9 & 39.3 \\
\hline
\end{tabular}

Source: Modhupur Upazila Expanded Program on Immunization registrar 2011-2013. upazila health complexes (fixed sites) which operate for 1-6 days per week for vaccinations. Each ward consists of eight vaccination sites (ie, ORCs). Each week, vaccination services are provided at two vaccination sites. Vaccination in rural wards is provided primarily by the HA, an employee of the health wing of the Ministry of Health and Family Welfare (MOH \& FW) and is usually assisted by family welfare assistant (FWA), an employee of the family planning wing of the $\mathrm{MOH} \& \mathrm{FW}$. In some instances, whenever the post of HA is vacant, the primary responsibility of vaccination is carried out by the FWA or by volunteers supported by the Global Alliance for Vaccines and Immunization. Porters carry vaccines from the upazila EPI cold room of the Upazila Health Complex (UHC) to the vaccination sites (ORCs) directly or through distribution points. Almost all EPI outreach sites are within 15-20 min (half an hour) walking distance. The field workers have universal instruction to perform home visits to register newborns (in the EPI Registration Book) and invite parents to bring their children to vaccination sessions on the day prior to an EPI session (which is called intrapersonal communication), thus performing an important social mobilisation role.

\section{Monitoring process}

EPI sessions are routinely monitored by the assistant health inspector (AHI) from the health site and the family planning inspector from the family planning site. Each union is supervised by one AHI, and the health inspector supervises the three unions.

\section{Variables considered during analysis \\ Fully vaccinated}

Children who received doses of the 'standard eight' antigens-one dose of BCG, three doses of pentavalent (including diphtheria-pertussis-tetanus, Hib and Hep B), polio (three doses) and one dose of measles vaccineswere considered fully vaccinated (figure 1).

\section{Not vaccinated}

A child was considered not vaccinated if he/she had received none of the above-mentioned vaccines.

\section{Rural}

Aushnara, Solakuri and Aronkhola unions of Modhupur upazila under Tangail district were considered as rural areas.

\section{Crude vaccination coverage}

Vaccines were received irrespective of vaccination schedule, such as the recommended ages and intervals between doses for each antigen.

\section{Invalid vaccination}

Vaccines were received not following the EPI vaccination schedule for the exact ages and dose intervals (provided before minimum interval periods) for each antigen. 
Valid vaccination

Vaccines were received following EPI-recommended exact ages and dose intervals for each antigen.

\section{Spot registration}

The eligible child is registered for vaccination at the vaccination site 28 days after birth.

\section{Timely registration}

The eligible child is registered for vaccination within 28 days of birth.

\section{Analysis plan}

After reviewing for completeness and accuracy, all the data were included in a database. Descriptive analysis was performed to determine the distribution of variables of general interest. Bivariate analysis was conducted to examine associations between dependent and independent variables. The significance level of the association was set at $\mathrm{p}<0.05$ with a $95 \%$ CI. The strength of association was calculated through ORs, and confounding was adjusted by applying multinomial logistic regression analysis. Data analysis was performed using SPSS V.20.

\section{Patient and public involvement}

The study data were extracted from the child immunisation registrar under the department of EPI with proper permission from DGHSs of MOH \& FW. The dissemination of the study findings to the study participants will be done through respective health managers with sharing the published manuscript.

\section{RESULTS}

In total, 2802 respondents were included in the study from the three unions $(39.5 \%$ from Aushnara, 35.1\% from Oronkhola and 25.4\% from Sholakuri) of the Madhupur subdistrict under the Tangail district in Bangladesh. Table 2 represents the associations between different characteristics of the children (eg, ethnicity, sex, religion, having a mobile phone or not, having spot registration or not, having timely registration or not). Analysis was conducted using the available data in percentages $(\%)$ for three categories: vaccine on time (ie, valid vaccination), vaccine at the wrong time (ie, invalid vaccination) and not vaccinated. The table shows that the proportion of valid vaccinations among tribal children was higher than that among non-tribal children (90.6\% vs $87.3 \%)$, whereas more non-tribal children were vaccinated at the wrong time or were not vaccinated; these figures were not statistically significant $(\mathrm{p}=0.25)$.

Among the three study areas, Oronkhola union had the highest valid vaccination coverage $(89.7 \%)$, Aushnara union had the lowest valid vaccination coverage $(85.8 \%)$ and Oronkhola had the highest percentage of children $(7.0 \%)$ who were not vaccinated (table 2 ). In terms of gender, valid vaccination coverage was higher among male children $(89.2 \%)$ than female children $(85.9 \%)$, and comparatively more female children were not vaccinated
Table 2 Association between characteristics of children and three different categories of vaccination status in Madhupur subdistrict

\begin{tabular}{|c|c|c|c|c|}
\hline \multirow[b]{2}{*}{ Characteristic } & \multicolumn{3}{|c|}{ Vaccination status $(n=2802)$} & \multirow[b]{2}{*}{$\begin{array}{l}P \\
\text { values }\end{array}$} \\
\hline & $\begin{array}{l}\text { Valid } \\
\text { vaccination } \\
(\mathrm{n}=2454) \\
\% \\
\end{array}$ & $\begin{array}{l}\text { Invalid } \\
\text { vaccination } \\
(\mathrm{n}=172) \\
\%\end{array}$ & $\begin{array}{l}\text { Not } \\
\text { vaccinated } \\
(n=176) \\
\% \\
\end{array}$ & \\
\hline \multicolumn{4}{|l|}{ Ethnicity } & 0.25 \\
\hline Tribal & 90.6 & 4.1 & 5.3 & \\
\hline Non-tribal & 87.3 & 6.4 & 6.3 & \\
\hline \multicolumn{4}{|l|}{ Union } & 0.00 \\
\hline Aushnara & 85.8 & 8.0 & 6.2 & \\
\hline Oronkhola & 89.7 & 3.3 & 7.0 & \\
\hline Solakuri & 87.3 & 7.2 & 5.5 & \\
\hline \multicolumn{4}{|l|}{ Sex } & 0.03 \\
\hline Male & 89.3 & 5.4 & 5.3 & \\
\hline Female & 85.9 & 6.9 & 7.2 & \\
\hline \multicolumn{4}{|l|}{ Religion } & 0.11 \\
\hline Muslim & 87.0 & 6.4 & 6.6 & \\
\hline Others & 91.1 & 4.6 & 4.3 & \\
\hline \multicolumn{4}{|l|}{ Has mobile } & 0.01 \\
\hline Yes & 90.9 & 4.5 & 4.6 & \\
\hline No & 86.5 & 6.7 & 6.8 & \\
\hline \multicolumn{4}{|l|}{ Spot registration } & 0.26 \\
\hline Yes & 88.0 & 5.9 & 6.1 & \\
\hline No & 85.0 & 7.5 & 7.5 & \\
\hline \multicolumn{4}{|c|}{ Timely registration } & 0.31 \\
\hline Yes & 87.9 & 6.4 & 5.7 & \\
\hline No & 87.2 & 5.8 & 7.0 & \\
\hline
\end{tabular}

than male children $(7.2 \%$ vs $5.3 \%)$. This finding was also statistically significant $(p=0.03)$. From the same table, we can note that the valid vaccination coverage was higher among the children of mobile phone users than among children of individuals who did not have mobile phones $(90.9 \%$ vs $86.5 \%)$, and a higher proportion of children of mobile phone non-users were not vaccinated compared with children of mobile phone users (6.9\% vs $4.5 \%)$. The religion, spot registration and timely registration categories did not have a significant role in vaccination coverage. To confirm the results from table 2, we developed a model to run multinomial logistic regressions. We retained all the variables used in table 2 for regression analysis (table 3), except for spot registration and timely registration, as these two variables were not significantly associated with EPI coverage. From table 3, we can deduce that children in Oronkhola union were $56 \%$ less likely to have invalid vaccination (OR: 0.44 , CI: 0.28 to $0.69, \mathrm{p}=0.001$ ) than children in other unions, and males were $28 \%$ less likely to not be vaccinated (OR: 0.72 , CI: 0.53 to $0.98, \mathrm{p}=0.04$ ) than females. It can also be noted from the same table that the children of individuals who 
Table 3 Multinomial logistic regression coefficients of covariates for different vaccination status in the three selective study areas

\begin{tabular}{|c|c|c|c|c|c|c|c|c|}
\hline \multirow[b]{4}{*}{ Variables } & \multicolumn{8}{|c|}{ Vaccine status $(n=2802)$} \\
\hline & \multicolumn{4}{|c|}{ Invalid vaccination $(n=172)$} & \multicolumn{4}{|c|}{ Not vaccinated $(n=176)$} \\
\hline & \multirow[b]{2}{*}{ AOR } & \multicolumn{2}{|l|}{$95 \% \mathrm{Cl}$} & \multirow[b]{2}{*}{$P$ values } & \multirow[b]{2}{*}{ AOR } & \multicolumn{2}{|l|}{$95 \% \mathrm{Cl}$} & \multirow[b]{2}{*}{$P$ values } \\
\hline & & Lower & Upper & & & Lower & Upper & \\
\hline \multicolumn{9}{|l|}{ Ethnicity } \\
\hline Tribal & 0.71 & 0.26 & 1.95 & 0.50 & 2.10 & 0.65 & 6.75 & 0.21 \\
\hline Non-tribal & 1.00 & & & & 1.00 & & & \\
\hline \multicolumn{9}{|l|}{ Union } \\
\hline Aushnara & 1.05 & 0.72 & 1.52 & 0.82 & 1.01 & 0.67 & 1.54 & 0.95 \\
\hline Oronkhola & 0.44 & 0.28 & 0.69 & 0.00 & 1.28 & 0.85 & 1.93 & 0.25 \\
\hline Sholakuri & 1.00 & & & & 1.00 & & & \\
\hline \multicolumn{9}{|l|}{ Sex } \\
\hline Male & 0.74 & 0.54 & 1.02 & 0.06 & 0.72 & 0.53 & 0.98 & 0.04 \\
\hline Female & 1.00 & & & & 1.00 & & & \\
\hline \multicolumn{9}{|l|}{ Religion } \\
\hline Muslim & 1.02 & 0.43 & 2.41 & 0.97 & 2.89 & 0.94 & 8.91 & 0.06 \\
\hline Other & 1.00 & & & & 1.00 & & & \\
\hline \multicolumn{9}{|c|}{ Has mobile phone or not } \\
\hline No mobile & 1.29 & 0.86 & 1.93 & 0.22 & 1.68 & 1.12 & 2.51 & 0.01 \\
\hline Has mobile & 1.00 & & & & 1.00 & & & \\
\hline
\end{tabular}

Reference category: valid vaccination.

AOR, adjusted OR.

did not have mobile phones were $68 \%$ more likely to not be vaccinated (OR: 1.68 , CI: 1.12 to $2.51, \mathrm{p}=0.01$ ) than children of individuals who had mobile phones.

\section{DISCUSSION}

This study is the first to provide a comprehensive overview of the EPI coverage on the basis of sociodemographic factors and to report the distribution of immunisation among tribal and non-tribal children in Bangladesh. Although the EPI has been active since 1979, Bangladesh has not yet achieved 100\% coverage of immunisation for children. There is also insufficient data for hard-to-reach areas in Bangladesh. Thus far, no study has reported on the equal distribution of vaccination coverage in rural Bangladesh, and no study has been found that has explored the reasons for the failure to achieve full EPI coverage in Bangladesh.

There is no doubt that the EPI has played a significant role in reducing the disease burden and child mortality in the country through vaccination. As stated in the EPI Coverage Evaluation Survey 2015, the vaccination coverage rate increased from $76.0 \%$ (in 1995) to $93.2 \% .{ }^{19-21}$ The current study provides a different picture of the vaccination coverage in the three study areas (approximately 86\%, 90\% and 88\% children had valid or completed vaccination in Aushnara, Oronkhola and Sholakuri union, respectively) (table 2). From these findings, it is evident that vaccination coverage is not distributed equally throughout Bangladesh, and the numbers of invalid doses are still alarming which prevents a successful outcome of the EPI. However, the same and higher coverage of full vaccination $(73.33 \%$ and $84.09 \%$, respectively) has been revealed by various other studies. ${ }^{33}$

As a whole, the conversion of invalid doses into valid doses would help to increase the total EPI coverage and would be helpful in preventing the aforementioned deadly diseases. As shown in table 2, Oronkhola union had the highest valid vaccination coverage $(89.7 \%)$, although the coverage in other study areas was not far from this figure. Surprisingly, Oronkhola union also had the highest percentage of children who were not vaccinated $(7.0 \%)$. Therefore, high vaccination coverage does not always indicate the success of the EPI. The higher vaccination coverage in Oronkhola union could be attributed to a high prevalence of mobile phone users (data not shown). However, communication does not always occur between participants and the field workers which requires attention from managers to further improve the coverage in Oronkhola.

Some studies have attempted to determine the causes of dropouts from immunisation programmes. Explanations provided include a lack of awareness about the vaccination services, fear of side effects, obstacles in both the supply and demand sites, inadequate household 
visits by the community-level health workers and a lack of reviewing dropout cases during vaccination sessions. ${ }^{19-21}$ Although the current study did not intend to explore those issues, this study found sex and the use of mobile phones as the major factors related to vaccination coverage. This study found that female children had less vaccination coverage than male children, and this difference was statistically significant (tables 2 and 3). Somewhat similar findings were seen in the study conducted by Khargekar et al which showed a higher percentage of immunisation in male children $(61.3 \%)$ than in female children $(38.8 \%){ }^{34}$ Another study conducted in India also found similar results, reporting that $87.61 \%$ of male children received vaccinations compared with $85.57 \%$ of female children. ${ }^{19}$ Accessibility to mobile phones played a significant role $(\mathrm{p}<0.05)$ in vaccination coverage, and the proportion of non-vaccinated children was higher among the individuals who did not have mobile phones (table 2 and table 3 ). There are several studies demonstrating that mobile phones help in improving immunisation coverage $^{30}{ }^{35-37}$ This study also found that vaccination coverage was lower among non-tribal children compared with tribal children (table 2 and table 3 ) which indicates inequality in vaccination coverage.

The present study has several limitations. It did not report the availability of the health workforce involved with the EPI (eg, HAs and female welfare visitors). Furthermore, this study was also conducted on a small scale due to funding constraints; hence, the findings do not represent the overall picture for all of Bangladesh. Due to unavailability of certain data, more exploration of possible confounders was not possible. However, the study investigators wish to address these issues in future research.

\section{CONCLUSIONS}

In conclusion, this paper provides evidence that there is no difference in vaccination between tribal and non-tribal populations which is a strength of the current EPI. EPI is one of the most expensive, longest-running and successful programmes in Bangladesh. A large number of workers from governmental and non-governmental sectors have been deployed to ensure the success of this expanded programme on immunisation which aimed to provide immunisations for all children by 1990 in order to prevent the aforementioned six preventable diseases. ${ }^{12-14}$ Nevertheless, even with great effort from both sectors, all eligible children have not yet been vaccinated in rural Bangladesh. Therefore, to achieve full success and to save children from preventable diseases, it is mandatory to explore the issues obstructing the success of the EPI. Simultaneously, the monitoring and supervision system of the EPI should be further strengthened to ensure that all children become vaccinated irrespective of their socioeconomic conditions, including sex and religion. It is especially important that all children complete all doses of vaccines at the appropriate intervals and times. Female children should also be followed up properly, as this study found gender inequalities in terms of vaccination coverage.

\section{Author affiliations}

${ }^{1}$ Health System and Population Studies Division, International Centre for Diarrhoeal

Disease Research, Bangladesh (icddr,b), Dhaka, Bangladesh

${ }^{2}$ Expended Program on Immunization Department, Director General of Health Services (DGHS), Government of Bangladesh (GoB), Dhaka, Bangladesh

${ }^{3}$ Global Consortium for Public Health Research, Liverpool John Moores University, Liverpool, UK

${ }^{4}$ Community Skilled Birth Attendant Program, Obstetrical and Gynaecological Society of Bangladesh (OGSB), Mohammadpur, Bangladesh

Acknowledgements The study kindly acknowledges the efforts of field workers and their supervisors who helped during developing the final database of the study area. All authors also gratefully acknowledge the following donors who provide unrestricted support to icddr,b: Government of the People's Republic of Bangladesh Global Affairs Canada (GAC); Swedish International Development Cooperation Agency (Sida) and the Department for International Development, (UKAid).

Contributors AR conceptualised the study. AR, AASR and BAB wrote the first draft of this protocol with substantial inputs from all authors. SDG organised and cleaned the data and participated in the analysis with AR, NA, BAB, SM and IA. AR, NA, AASR, IA, SD, BAB and SM contributed to the interpretation. All the authors were involved in developing the manuscript and approved the final version for submission. All authors read and approved the final manuscript.

Funding The authors have not declared a specific grant for this research from any funding agency in the public, commercial or not-for-profit sectors.

Competing interests None declared.

Patient consent Not required.

Ethics approval This study has used the routine Expanded Program on Immunization (EPI) data but permission to use this data was approved by the EPI Directorate office. Any information about the study participant cannot be traced back and all the reports were presented anonymously.

Provenance and peer review Not commissioned; externally peer reviewed.

Data sharing statement Data can be available through icddr,b data access policy. Data can be accessed through contacting Research Administration Department of icddr,b by mailing to aahmed@icddrb.org.

Author note Findings of this study will be cared to publish at international peerreviewed journal for dissemination.

Open access This is an open access article distributed in accordance with the Creative Commons Attribution Non Commercial (CC BY-NC 4.0) license, which permits others to distribute, remix, adapt, build upon this work non-commercially, and license their derivative works on different terms, provided the original work is properly cited, appropriate credit is given, any changes made indicated, and the use is non-commercial. See: http://creativecommons.org/licenses/by-nc/4.0/.

\section{REFERENCES}

1. Jamil K, Bhuiya A, Streatfield K, et al. The immunization programme in Bangladesh: impressive gains in coverage, but gaps remain. Health Policy Plan 1999;14:49-58.

2. Abdu H. Assessment of Maternal Satisfaction Towards Childhood Immunization and Its Associated Factors in $\mathrm{MCH}$ Clinic, at Kombolcha, in Amhara Regional State, Northern Ethiopia. Addis Ababa: Addis Ababa University, 2015.

3. Islam T. Child Immunization Programme of ICDS: Case Study of Patna. Available at SSRN 22034442013.

4. Lee K. The World Health Organization (WHO). Routledge, 2008.

5. Lopez AD, Mathers CD, Ezzati M, et al. Global and regional burden of disease and risk factors, 2001: systematic analysis of population health data. Lancet 2006;367:1747-57.

6. Salisbury D, Ramsay M, Noakes K. Immunisation against infectious disease. London: The Stationery Office, 2006.

7. Fauci AS. Infectious diseases: considerations for the 21 st century. Clin Infect Dis 2001;32:675-85.

8. Nabel GJ. Designing Tomorrow's Vaccines. N Engl J Med Overseas Ed 2013;368:551-60. 
9. Kerber KJ, de Graft-Johnson JE, Bhutta ZA, et al. Continuum of care for maternal, newborn, and child health: from slogan to service delivery. Lancet 2007;370:1358-69.

10. Jamison DT, Breman JG, Measham AR, et al. Disease control priorities in developing countries. Washington, DC: World Bank 2006.

11. World Health Organization. The world health report 2002: reducing risks. promoting healthy life: World Health Organization 2002.

12. Smith KA. Edward jenner and the small pox vaccine. Front Immunol 2011;2:21.

13. Hardon A, Blume S. Shifts in global immunisation goals (1984-2004): unfinished agendas and mixed results. Soc Sci Med 2005;60:345-56.

14. Bryce J, Boschi-Pinto C, Shibuya K, et al. WHO estimates of the causes of death in children. Lancet 2005;365:1147-52.

15. John TJ, Vashishtha VM. Eradicating poliomyelitis: India's journey from hyperendemic to polio-free status. Indian J Med Res 2013;137:881-94.

16. Kimman TG, Boot $\mathrm{H}$. The polio eradication effort has been a great success-let's finish it and replace it with something even better. Lancet Infect Dis 2006;6:675-8.

17. Liu L, Oza S, Hogan D, et al. Global, regional, and national causes of child mortality in 2000-13, with projections to inform post-2015 priorities: an updated systematic analysis. Lancet 2015;385:430-40.

18. Khan AA, Zahidie A, Rabbani F. Interventions to reduce neonatal mortality from neonatal tetanus in low and middle income countries-a systematic review. BMC Public Health 2013;13:322.

19. Gupta PK, Pore P, Patil U. Evaluation of immunization coverage in the rural area of pune, maharashtra, using the 30 cluster sampling technique. J Family Med Prim Care 2013;2:50.

20. Kassahun MB, Biks GA, Teferra AS. Level of immunization coverage and associated factors among children aged 12-23 months in Lay Armachiho District, North Gondar Zone, Northwest Ethiopia: a community based cross sectional study. BMC Res Notes 2015;8:1):1.

21. Ismail IT, El-Tayeb EM, Omer MD, et al. Assessment of routine immunization coverage in nyala locality, reasons behind incomplete immunization in south darfur state, sudan. Asian J Med Sci 2014;6:1-8

22. Mathew JL. Inequity in childhood immunization in India: a systematic review. Indian Pediatr 2012;49:203-23.

23. Maurice JM, Davey S. State of the world's vaccines and immunization. Geneva: World Health Organization, 2009.
24. UNICEF. Health and nutrition-expanded immunization. 2016 https:// www.unicef.org/emailarticle/bangladesh/health_nutrition_468.rhtm (accessed 11 January 2016)

25. World Health Organization, 2017. Bangladesh: home-grown solutions helped stop polio and keep this country polio-free]. cited 23 May 2017 http://www.searo.who.int/entity/immunization/topics/polio/ eradication/bangladesh-home-grown-polio-solutions/en/ (accessed 23 May 2017).

26. Franco E, Bagnato B, Marino MG, et al. Hepatitis B: Epidemiology and prevention in developing countries. World $\mathrm{J}$ Hepatol 2012;4:74-80.

27. Watt JP, Wolfson LJ, O'Brien KL, et al. Burden of disease caused by Haemophilus influenzae type $b$ in children younger than 5 years: global estimates. Lancet 2009;374:903-11.

28. Vashishtha VM, Yewale VN, Bansal CP, et al. IAP perspectives on measles and rubella elimination strategies. Indian Pediatr 2014;51:719-22.

29. Rahman M, Obaida-Nasrin S. Factors affecting acceptance of complete immunization coverage of children under five years in rural Bangladesh. Salud Publica Mex 2010;52:134-40.

30. Uddin MJ, Saha NC, Islam Z, et al. Improving low coverage of child immunization in rural hard-to-reach areas of Bangladesh: findings from a project using multiple interventions. Vaccine 2012;30:168-79.

31. Director General of Health Services. Bangladesh EPI Coverage Evaluation Survey 2014. Dhaka 2015.

32. UNICEF. UNICEF Annual Report 2010: UNICEF, 2011.

33. K P, K L, G S, et al. Evaluation of primary immunization coverage of infants under universal immunization programme in an urban area of bangalore city using cluster sampling and lot quality assurance sampling techniques. Indian J Community Med 2008;33:151.

34. Khargekar NC, Khargekar VC, Shingade PP. Immunization status of children under 5 years in a tribal area, parol, thane district. National Journal of Community Medicine 2015;6:522-7.

35. Kazi AM, Jafri LA. The use of mobile phones in polio eradication. Bull World Health Organ 2016;94:153-4.

36. Vilella A, Bayas JM, Diaz MT, et al. The role of mobile phones in improving vaccination rates in travelers. Prev Med 2004;38:503-9.

37. Uddin MJ, Shamsuzzaman M, Horng L, et al. Use of mobile phones for improving vaccination coverage among children living in rura hard-to-reach areas and urban streets of Bangladesh. Vaccine 2016;34:276-83 